\title{
Development of an Offline-Friend Addiction Questionnaire (O-FAQ): Are most people really social addicts?
}

\author{
Liam P. Satchell ${ }^{1}$ (D) Dean Fido ${ }^{2}$ - Craig A. Harper $^{3} \cdot$ Heather Shaw $^{4} \cdot$ Brittany Davidson $^{5} \cdot$ David A. Ellis $^{6}$. \\ Claire M. Hart ${ }^{7} \cdot$ Rahul Jalil $^{8} \cdot$ Alice Jones Bartoli $^{9} \cdot$ Linda K. Kaye $^{10} \cdot$ Gary L. J. Lancaster $^{1} \cdot$ Melissa Pavetich $^{11}$
}

Published online: 24 September 2020

(C) The Psychonomic Society, Inc. 2020

\begin{abstract}
A growing number of self-report measures aim to define interactions with social media in a pathological behavior framework, often using terminology focused on identifying those who are 'addicted' to engaging with others online. Specifically, measures of 'social media addiction' focus on motivations for online social information seeking, which could relate to motivations for offline social information seeking. However, it could be the case that these same measures could reveal a pattern of friend addiction in general. This study develops the Offline-Friend Addiction Questionnaire (O-FAQ) by re-wording items from highly cited pathological social media use scales to reflect "spending time with friends". Our methodology for validation follows the current literature precedent in the development of social media 'addiction' scales. The O-FAQ had a three-factor solution in an exploratory sample of $N=807$ and these factors were stable in a 4-week retest ( $r=.72$ to .86 ) and was validated against personality traits, and risk-taking behavior, in conceptually plausible directions. Using the same polythetic classification techniques as pathological social media use studies, we were able to classify $69 \%$ of our sample as addicted to spending time with their friends. The discussion of our satirical research is a critical reflection on the role of measurement and human sociality in social media research. We question the extent to which connecting with others can be considered an 'addiction' and discuss issues concerning the validation of new 'addiction' measures without relevant medical constructs. Readers should approach our measure with a level of skepticism that should be afforded to current social media addiction measures.
\end{abstract}

Keywords Measurement $\cdot$ Social addiction $\cdot$ Social information $\cdot$ Social media addiction $\cdot$ Social time $\cdot$ Validation

\section{Introduction}

The role that technology plays in modern life continues to provoke debate in academic literature and across popular media (e.g., Stieger \& Lewetz, 2018; Twenge, 2017). Social media remains core to many of these concerns as it has radically changed the way we socialize. For example, social networking sites and online messaging

We note that Dean Fido, Craig Harper and Heather Shaw are considered equal second authors. All other authors are arranged alphabetically.

Liam P. Satchell

liam.satchell@winchester.ac.uk

1 Department of Psychology, University of Winchester, Sparkford Road, Winchester, Hampshire SO22 4NR, UK

2 College of Business, Law and Social Sciences, University of Derby, Derby, UK

3 Department of Psychology, Nottingham Trent University, Nottingham, UK

4 Department of Psychology, Lancaster University, Lancaster, UK

5 Department of Computer Science, University of Bristol, Bristol, UK
6 School of Management, University of Bath, Bath, UK

7 School of Psychology, University of Southampton, Southampton, UK

8 Department of Psychology, Birmingham City University, Birmingham, UK

9 Department of Psychology, Goldsmiths, University of London, London, UK

10 Department of Psychology, Edge Hill University, Ormskirk, UK

11 School of Human Sciences, University of Greenwich, London, UK 
services, such as Facebook, present opportunities for users to instantly share social information with large numbers of people (Subrahmanyam, Reich, Waechter, \& Espinoza, 2008). These activities are elementary to the basic human need for obtaining social information and relatedness (Day, Ong, \& Perry, 2018), and avoiding loneliness and isolation (Martín-Albo et al., 2015). Indeed, engaging with some elements of social media has been found to improve psychosocial well-being (Chan, 2018a, 2018b; Ellison, Steinfield, \& Lampe, 2007; Obst \& Stafurik, 2010; Wang, Brede, Ianni, \& Mentzakis, 2018) and frequent social media use has been related to reduced loneliness, through users' feelings of satisfaction with their connections to friends (Deters \& Mehl, 2013; Sheldon, Abad, \& Hinsch, 2011). Conversely, a large body of research demonstrates associations between heightened online social information seeking, known as 'social media addiction', and negative outcomes including low selfesteem and life satisfaction (Andreassen, Pallesen, \& Griffiths, 2017; Błachnio, Przepiorka, \& Pantic, 2016). Further, those who report higher levels of loneliness also estimate increased Facebook use (Błachnio \& Przepiorka, 2019). Establishing causality remains challenging, however. While Facebook may increase loneliness following social comparisons, people could simply seek more social information as a form of comfort (Wang et al., 2018).

This research overwhelmingly reports high rates of social media 'addiction' (up to $34 \%$ of some samples, see review by Andreassen, 2015). This reported rate of addiction is cause for concern, especially as this might be reflected in other social behaviors. For example, individuals frequently seek social information in offline contexts. Increased offline social time comes with risks, too, as face-to-face social pressure can lead to increased risktaking behavior, such as in 'peer pressure' situations (Gheorghiu, Delhomme, \& Felonneau, 2015; Lewis \& Lewis, 1984). With the danger of increased offline social behavior and the measurement practices in social media addiction research, we considered how we could adopt similar approaches to measuring behavioral addiction to evaluate 'offline friend addiction'. In doing so, we assess the prevalence of addictive behaviors in an alternative social context, which might be driven by similar parallel psychological processes. For example, self-determination theory highlights that individuals' well-being is associated with their relatedness with others (Deci \& Ryan, 1985), and this is correlates with daily mood, whereby increased seeking of social contact aligns with more positive mood (Reis, Sheldon, Gable, Roscoe, \& Ryan, 2000). Research has shown that social media use is also relevant for relatedness (Lin, 2016), and it could be the case that spending time with friends offline meets this need as well. While it is the case that there are psychological traits that influence a need to seek social information from others, to our knowledge, no social media addiction research has accounted for the role of offline friend addiction behavior.

Here, we follow the social media addiction literature closely to create and validate the Offline-Friend Addiction Questionnaire (O-FAQ) by re-wording existing measures. For example, the Social Media Craving Scale was previously adapted from the Penn Alcohol Craving Scale (Savci \& Griffiths, 2019) and the Facebook Intrusion Questionnaire from the Mobile Phone Involvement Questionnaire (Elphinston \& Noller, 2011). While we do not currently have a psychiatric (medical) criteria to validate our scale, we can use self-reported personality traits (see Andreassen, Torsheim, Brunborg, \& Pallesen, 2012; Orosz, Tóth-Király, \& Böthe, 2016), self-reported problematic behaviors (see Andreassen et al., 2012; Savci \& Griffiths, 2019), and self-reported estimates of spent socially interacting (Elphinston \& Noller, 2011; Orosz et al., 2016; Savci \& Griffiths, 2019) as proxies for our target construct. We can also use our validation measures of risk-taking behavior to highlight the dangers of offline social behavior. Following the practice in the literature, we also aim to categorize participants as being addicted to spending time with their friends. To do this, we follow the frequently cited 'polythetic' classifying criteria from Adreasson et al. (Andreassen et al., 2012) to define an addict as an individual who scores 'neither agree nor disagree' on one more than half of the items in our questionnaire (examples following this guidance include Brailovskaia, Schillack, \& Margraf, 2018; Brailovskaia, Margraf, \& Köllner, 2019; Gul, Yurumez Solmaz, Gul, \& Oner, 2018; Hou, Xiong, Jiang, Song, \& Wang, 2019; Jafarkarimi, Sim, Saadatdoost, \& Hee, 2016; Rajesh \& Rangaiah, 2020; Sampath, Kalyani, Soohinda, \& Dutta, 2017).

The aim of this study (as declared in our pre-registration: https://osf.io/9y2rh//) is that by following the typical methods of social media addiction research, we will be able to develop, validate, and establish reliability of a scale that categorizes individuals as addicted to their friends.

\section{Method}

Our aims, sample size, procedure, and analysis choices are detailed in our Open Science Framework (OSF) pre-registration, which can be found here: https://osf.io/9y2rh/. This study received ethical approval from the University of Derby and the study was conducted to the standards of the Declaration of Helsinki and the British Psychological Society.

Participants This multi-lab study recruited an opportunity sample of undergraduate students from 11 different universities across the U.K. using participant pools and online advertising. 
Participants were eligible if they were at least 18 years of age and fluent in English. Our recruitment advert requested that individuals diagnosed with a mental health condition (such as bipolar disorder, schizophrenia, or any condition that has required hospitalization over the last 12 months, not including depression or anxiety) did not take part in the study. Our data collection stopping rule (see preregistration) was to collect enough data so that we could adequately analyze test-retest data from at least 320 participants who had completed Time 1 and Time 2 responses (to detect a minimum correlation of $r=.20$, assuming $\alpha$ and $\beta$ of $.05)$. We stopped Time 1 recruitment when we had collected $N=$ 328 complete Time 2 responses. We then waited 28 days for the last of the Time 2 reports.

At Time 1, 1039 individuals engaged with the survey link. Of these, $N=807$ participants completed all Time 1 measures $\left(n_{\text {Female }}=640, n_{\text {Male }}=161, \mathrm{M}_{\text {Age }}=28.36, \mathrm{SD}_{\mathrm{Age}}=11.68\right)$ and their data was retained for analysis. The majority of these participants were from the UK $\left(n_{\mathrm{UK}}=593\right)$.

At Time 1, participants could elect to provide their email address for a test-retest 28 days after their initial submission. After removing the participants whose Time 2 identifying codes did not match any Time 1 codes, $N=$ $313\left(n_{\text {Female }}=250, n_{\text {Male }}=58, \mathrm{M}_{\text {Age }}=28.93, \mathrm{SD}_{\mathrm{Age}}=\right.$ $12.54, n_{\mathrm{UK}}=243$ ) participants remained for test-retest analysis.

Materials Our full questionnaire, with all questions as presented to participants, can be found in our OSF materials.

Offline-Friend Addiction Questionnaire (O-FAQ). The O-FAQ was adapted from previous measures of pathological social media use. We reframed established measures' items to assess our target construct. We adapted the Bergen Facebook Addiction Scale (Andreassen et al., 2012; cited by 969 at time of writing), the Facebook Instruction Scale (Elphinston \& Noller, 2011; cited by 472), the Facebook Intensity Scale ${ }^{1}$ (Orosz et al., 2016; cited by 52), and the most recent Social Media Craving Scale (Savci \& Griffiths, 2019) by changing references to 'Facebook' or 'Social Media' to 'spending time with friends'. Some items required additional adaptation to be suitable (most notably the Social Media Craving Scale's items, which use a different response format). The complete O-FAQ had 37 items and is presented in

\footnotetext{
${ }^{1}$ Although the Facebook Intensity Scale (Orosz et al., 2016) "aimed to create a scale which is relevant to general Facebook users, and which does not focus on the pathologic or addiction-related aspects of Facebook use" (p. 96), they do conclude that their scale factors of Persistence can "lead to obsessive passion and addiction towards Facebook" (p. 102) and Overuse "is related to the excessive use and addictive dimensions Facebook as previously assessed by Andreassen et al" (p. 102). With these factors in mind, we include the scale in our study as the measure highlights the same larger theoretical questions about social behavior as distinct to Facebook.
}

Table 1. This measure was responded to on a scale of Strongly Disagree (1) to Strongly Agree (5).

Validation measures. In line with the aims of the study, we used social media addiction literature precedent to validate the O-FAQ. In all cases, aggregate factor scores of existing measures were retained for analysis.

To demonstrate that the O-FAQ shares variance with other measures of social preference and anxiety), we examined the relationship between the O-FAQ and the Big Five personality traits (as per Andreassen et al., 2012; Orosz et al., 2016). We used the Big Five Inventory (John, Naumann, \& Soto, 2008) which showed good internal reliability in our Time 1 data for Conscientiousness $\left(\alpha=.79, \mathrm{M}_{\mathrm{C}}=3.52, \mathrm{SD}_{\mathrm{C}}=0.64\right)$, Agreeableness $\left(\alpha=.74, \mathrm{M}_{\mathrm{A}}=3.84, \mathrm{SD}_{\mathrm{A}}=0.61\right)$, Neuroticism $\left(\alpha=.85, \mathrm{M}_{\mathrm{N}}=3.32, \mathrm{SD}_{\mathrm{N}}=0.82\right)$, Openness $\left(\alpha=.77, \mathrm{M}_{\mathrm{O}}=3.53, \mathrm{SD}_{\mathrm{O}}=0.61\right)$, and Extraversion $(\alpha=$ $\left..87, \mathrm{M}_{\mathrm{E}}=3.16, \mathrm{SD}_{\mathrm{E}}=0.85\right)$.

To demonstrate convergent validity with other measures of problematic behavior (as per Andreassen et al., 2012; Savci \& Griffiths, 2019), we included a measure of Domain Specific Risk Taking (DOSPERT; Blais \& Weber, 2006). The DOSPERT contains 30-items assessing different types of risk-taking. At Time 1, the reliability of the DOSPERT items were on the lower end of acceptable for Social $(\alpha=.63, \mathrm{M}=$ 5.01, $\mathrm{SD}=0.99)$, Recreational $(\alpha=.80, \mathrm{M}=3.22, \mathrm{SD}=1.48)$, Ethical $(\alpha=.60, \mathrm{M}=2.18, \mathrm{SD}=0.87)$, Financial $(\alpha=.75, \mathrm{M}$ $=2.22, \mathrm{SD}=0.99)$, and Health $(\alpha=.64, \mathrm{M}=3.16, \mathrm{SD}=1.18)$ risk-taking.

To demonstrate that the scale is measuring the engagement with the behavior in question, we were guided by previous research (Elphinston \& Noller, 2011; Orosz et al., 2016; Savci \& Griffiths, 2019) and asked "In the past 7 days, how many hours have you spent with friends (in person)?" At Time 1, participants reported spending on average 18.36 hours with friends in person $\left(\mathrm{SD}_{\mathrm{w} / \text { friends } 1}=22.34\right)$ and 16.33 hours at Time $2\left(\mathrm{SD}_{\mathrm{w} / \text { friends } 2}=21.06\right)$. Individuals were notably consistent in their amount of in-person friend contact across the four-week period ( $\alpha=.77, d=0.09$ ).

Procedure Participants were recruited for an online questionnaire on 'personality and friendship'. After consenting, respondents provided demographic information (age, gender, home country) and how much time they spent with their friends over the last week (in person). Participants then completed the O-FAQ, then the Big Five measure, and finally the DOSPERT. They also created a unique identifying code for the confidential matching of their Time 1 and Time 2 data and provided an e-mail address to be contacted for a follow-up.

At Time 2 participants were asked how much time they spent with their friends over the last week (in person) and completed the O-FAQ for a second time. 
Table 1 Sources, descriptive statistics, and exploratory factor analysis loadings from exploratory factor analysis of the Offline-Friend Addiction Questionnaire

\begin{tabular}{|c|c|c|c|c|c|c|}
\hline \# & Source & Item & $\begin{array}{l}\mathrm{M}(\mathrm{SD}) \\
1-5 \text { scale }\end{array}$ & $\begin{array}{l}\text { Social } \\
\text { rumination } \\
(\alpha=.91)\end{array}$ & $\begin{array}{l}\text { Life } \\
\text { disruption } \\
(\alpha=.83)\end{array}$ & $\begin{array}{l}\text { Affective } \\
\text { reactions } \\
(\alpha=.83)\end{array}$ \\
\hline 1 & BFAS & I spend a lot of time thinking about spending time with friends & $3.25(1.08)$ & .62 & .04 & .22 \\
\hline 2 & BFAS & I often think about how I could free up more time to spend with friends & $3.03(1.08)$ & .49 & .05 & .22 \\
\hline 3 & BFAS & I often think about the times I've spent with friends & $3.88(0.89)$ & .63 & .01 & .05 \\
\hline 4 & BFAS & I have spent more time with friends than I initially intended & $2.86(1.15)$ & .08 & .42 & -.04 \\
\hline 5 & BFAS & I have recently felt an urge to spend more and more time with friends & $3.27(1.14)$ & .38 & -.02 & .39 \\
\hline 6 & BFAS & $\begin{array}{l}\text { Lately, I feel I need to spend longer with friends get the same pleasure from hanging } \\
\text { out }\end{array}$ & $2.53(1.07)$ & .10 & .02 & .44 \\
\hline 7 & BFAS & I spend time with friends in order to forget about personal problems & $2.98(1.25)$ & -.01 & .11 & .70 \\
\hline 8 & BFAS & $\begin{array}{l}\text { I spend time with friends to reduce feelings of guilt, anxiety, helplessness, \& } \\
\text { depression }\end{array}$ & $3.06(1.26)$ & -.02 & .08 & .72 \\
\hline 9 & BFAS & I have spent time with friends in order to reduce feelings of restlessness & $3.16(1.20)$ & -.06 & .16 & .60 \\
\hline 10 & BFAS & I become restless or troubled if I cannot spend time with friends & $2.64(1.11)$ & .36 & .00 & .44 \\
\hline 11 & BFAS & I become irritable if I am unable to spend time with friends & $2.61(1.13)$ & .39 & .00 & .44 \\
\hline 12 & BFAS & I feel bad if I, for different reasons, cannot spend time with friends & $3.29(1.10)$ & .51 & -.06 & .14 \\
\hline 13 & BFAS & $\begin{array}{l}\text { I have spent so much time with friends that it has had a negative impact on my } \\
\text { job/studies }\end{array}$ & $1.97(1.05)$ & -.06 & .70 & -.01 \\
\hline 14 & BFAS & $\begin{array}{l}\text { I have given less priority to hobbies, leisure activities, and exercise because of } \\
\text { spending time with friends }\end{array}$ & $2.28(1.14)$ & .08 & .63 & .03 \\
\hline 15 & BFAS & $\begin{array}{l}\text { I have ignored my current/previous partner(s) or family members to spend time with } \\
\text { friends }\end{array}$ & $1.99(1.02)$ & -.07 & .60 & .04 \\
\hline 16 & FIQ & I often think about my friends when I'm not with them & $3.29(0.97)$ & 69 & .00 & .02 \\
\hline 17 & FIQ & I often spend time with friends for no particular reason & $3.19(1.12)$ & .36 & .36 & -.14 \\
\hline 18 & FIQ & $\begin{array}{l}\text { Arguments have arisen with others because of how I spent my time with some of my } \\
\text { friends }\end{array}$ & $1.83(0.91)$ & -.03 & .59 & .05 \\
\hline 19 & FIQ & I can interrupt whatever else I am doing when I feel the need to see my friends & $2.53(1.02)$ & .19 & .40 & -.10 \\
\hline 20 & FIQ & I feel connected to other people when I spend time with my friends & $3.75(0.88)$ & .36 & -.02 & .06 \\
\hline 21 & FIQ & I lose track of how much time I spend with my friends & $3.18(1.17)$ & .37 & .36 & -.11 \\
\hline 22 & FIQ & $\begin{array}{l}\text { The thought of not being able to spend time with my friends makes me feel } \\
\text { distressed }\end{array}$ & $2.94(1.16)$ & .63 & -.03 & .21 \\
\hline 23 & FIS & If I could do only one thing in a day, it would be to spend time with friends & $2.45(1.08)$ & .51 & .16 & .11 \\
\hline 24 & FIS & Spending time with friends is good for overcoming boredom & $3.81(0.98)$ & .31 & .04 & .13 \\
\hline 25 & FIS & I spend time with my friends at the expense of my obligations & $2.11(0.96)$ & .00 & .64 & .11 \\
\hline 26 & FIS & My friends know a lot about me & $3.88(1.00)$ & .61 & .03 & -.25 \\
\hline 27 & FIS & I feel bad if I don't spend time with my friends regularly & $3.20(1.09)$ & .66 & -.06 & .07 \\
\hline 28 & FIS & When I'm bored, I like to arrange to spend time with friends & $3.31(1.08)$ & .42 & .23 & .11 \\
\hline 29 & FIS & I spend more time with my friends than I would like to & $1.88(0.78)$ & -.21 & .62 & -.03 \\
\hline 30 & FIS & I like to catch up with my friends and keep them updated about my life & $3.78(0.92)$ & .81 & -.05 & -.22 \\
\hline 31 & FIS & I often try to find opportunities to spend time with friends & $3.46(1.01)$ & .71 & .07 & -.08 \\
\hline 32 & FIS & It happens that I spend time with friends instead of sleeping & $2.08(1.08)$ & .13 & .55 & .08 \\
\hline 33 & FIS & $\begin{array}{l}\text { It is important for me to regularly meet up with my friends regularly and update } \\
\text { them with details about my life }\end{array}$ & $3.15(1.08)$ & 69 & .09 & -.06 \\
\hline 34 & SMCS & $\begin{array}{l}\text { In the past week, I have often thought about how good spending time with friends } \\
\text { would make me feel }\end{array}$ & $3.23(1.15)$ & .58 & -.02 & .24 \\
\hline 35 & SMCS & $\begin{array}{l}\text { At the most challenging point of last week, I have a strong craving to spend time } \\
\text { with friends }\end{array}$ & $2.82(1.28)$ & .41 & .11 & .32 \\
\hline 36 & SMCS & $\begin{array}{l}\text { In the past week I have spent more than } 6 \text { hours thinking about spending time with } \\
\text { friends }\end{array}$ & $2.26(1.06)$ & .34 & .18 & .27 \\
\hline 37 & SMCS & $\begin{array}{l}\text { In the past week I have found it difficult to resist spending time with friends, if I had } \\
\text { the opportunity to do so }\end{array}$ & $2.82(1.12)$ & .30 & .46 & .15 \\
\hline
\end{tabular}

Notes BFAS= Bergen Facebook Addiction Questionnaire, FIQ= Facebook Intrusion Questionnaire, FIS= Facebook Intensity Scale, SMCS= Social Media Craving Scale

Analytical Strategy All analysis was conducted in R, and our code is available on the OSF (https://osf.io/9y2rh/).

Inference criteria. Our analytical choices are all stated a priori in our preregistration. Following the precedent for drawing inference in previous similar research, the results will be evaluated in null hypothesis tests (with $a=.05$ ), and we report the $95 \%$ CI of effect sizes.

Factor analysis criteria. We used exploratory factor analysis (EFA) to evaluate the structure of the O-FAQ. This EFA was conducted after reaching our preregistered criterion of $n>300$ completions at Time 1 , 
with the aim of producing a short-form measure within the 28 days before Time 2 . In line with previous research, we built a direct oblimin EFA (Elphinston \& Noller, 2011), and tested the data's suitability for EFA using Bartlett's sphericity test (accepting data for EFA where $p<.05$; Savci \& Griffiths, 2019). We then tested the acceptability of a one-factor solution (as others have done with social media addiction measures; Andreassen et al., 2012). If a one-factor solution was found to be adequate (see Table 2; Savci \& Griffiths, 2019), we preregistered that this model would be accepted.

Validation analyses. In line with our strategy to closely follow previous literature, we demonstrate the validity of the O-FAQ with; correlations between the O-FAQ and the Big Five traits (similarly to Andreasson et al., 2012; Orosz et al., 2016), correlations between the O-FAQ and the amount of time participants report spending with friends (in hours) (see Elphinston \& Noller, 2011), and correlations between the O-FAQ and problematic behavior (the DOSPERT; see Savci \& Griffiths, 2019). In line with previous work (Andreassen et al., 2012), we also conduct two step regressions predicting the O-FAQ domains with age, gender of participants, and time spent with friends in Step 1 and then Step 2 including the personality and risk-taking traits.

Consistency analysis. To demonstrate test-retest consistency, we conducted correlations between Time 1 and Time 2 O-FAQ domain scores.

'Addict' classification. Following previous literature, we categorically define 'addicts' in our sample. We will do this using the polythetic and monothetic criteria used by others. Specifically, we follow frequently cited guidance provided by Andreassen et al. (2012, p. 512), which defines a 'polythetic scoring scheme' as "scoring 3 or above [out of 5] on at least four of the six items" and a 'monothetic scoring key' as “(e.g., scoring 3 [out of 5] or above on all six items)". In our study, we will classify participants as addicts on the 'conservative' monothetic criteria of responding "neither agree nor disagree (3)" or higher $(\geq 3)$ on all items $(K)$. Further, we will classify participants as addicts on the 'liberal' polythetic criteria of responding "neither agree nor disagree (3)" or higher $(\geq$ $3)$ on the majority $((K / 2)+1)$ of items.

\section{Results}

Structure of Offline-Friend Addiction Questionnaire (O-FAQ) Before the 28-day cut-off point for our attempted item reduction, we had collected $n=421$ responses to the O-FAQ $\left(n_{\text {Female }}=319, n_{\text {Male }}=99, \mathrm{M}_{\text {Age }}=32.71, \mathrm{SD}_{\text {Age }}=12.37\right.$, $\left.n_{\mathrm{UK}}=273\right)$. We conducted an oblimin EFA on data suitable for factor analysis (Bartlett's sphericity test $\chi^{2}=7151.64, p<$ .001). We sought a one-factor solution for our data, which was not an adequate fit based on our preregistered criteria taken from Savci and Griffiths (2019), see Table 2. The closest fit to all the precedent-defined acceptable criteria was a sevenfactor solution. This would create multiple small factors with few items and was not considered an efficient solution to the factor analysis. Therefore, we chose to deviate from our preregistration criteria and adopted a three-factor solution which met the majority of the acceptability criteria (except TLI; Table 2). For item loadings, see Table 1 . There were no items that were low-loading by the criteria we established in our preregistration section $(<.30)$ and so we did not reduce the number of items in the O-FAQ for Time 2 assessment.

The first factor, labeled Social Rumination, contained 20 items reflecting preoccupied thoughts about spending time with others and using time with friends to avoid boredom. Items in this factor included; "I often think about the times I've spent with friends", "If I could do only one thing in a day, it would be to spend time with friends" and "At the most challenging point of last week, I have a strong craving to spend time with friends".

The second factor, labeled Life Disruption, summarized a preference of spending time with friends over other obligations. It contained 11 items, including; "I have spent so much time with friends that it has had a negative impact on my job/ studies", "It happens that I spend time with friends instead of sleeping", and "I have ignored my current/previous partner(s) or family members to spend time with friends".

The 7-item third factor, labeled Affective Reactions, included the responses where spending time with friends is a response to an emotional state. Items included; "I spend time with friends to reduce feelings of guilt, anxiety, helplessness, $\&$ depression", "I become irritable if I am unable to spend time with friends" and "Lately, I feel I need to spend longer with friends get the same pleasure from hanging out".

With the remaining Time 1 dataset not previously used for the first EFA $(n=386)$, we conducted a second EFA and replicated the exploratory structure fit in this independent sample $\left(\right.$ RMSEA $=.068,[.062, .070]$, TLI $=.78, \chi^{2} / d f=$ $3.87)$. We then conducted a confirmatory factor analysis on the complete Time 1 sample, using a diagonally weighted least-squares (DWLS) model suitable for our skewed data, which suggested the three-factor structure did meet the acceptable fit criteria $(\mathrm{RMSEA}=.080[.078, .083], \mathrm{TLI}=.94, \mathrm{CFI}=$ $\left..94, \chi^{2}=3666.33, p<.001\right)$, as was the case in the independent Time 2 data (RMSEA $=.05[.041, .051], \mathrm{TLI}=.98, \mathrm{CFI}=$ $\left..98, \chi^{2}=981.25, p<.001\right)$.

The aggregate response to each domain was retained for analysis and in the complete Time 1 sample. The Social Rumination scores were in the range of $\mathrm{M}_{\mathrm{SR}}=3.34, \mathrm{SD}_{\mathrm{SR}}=$ 0.63, $(\operatorname{Min}=1.00, \operatorname{Max}=5.00)$, Life Disruption scores were in the range of $\mathrm{M}_{\mathrm{LD}}=2.37, \mathrm{SD}_{\mathrm{LD}}=0.65,(\mathrm{Min}=1.00, \mathrm{Max}=$ 
4.64), and Affective Reactions scores were in the range of $\mathrm{M}_{\mathrm{AR}}=2.93, \mathrm{SD}_{\mathrm{AR}}=0.81,(\mathrm{Min}=1.00, \mathrm{Max}=5.00)$.

In the Time 2 dataset, the sample had Social Rumination scores in the range of $\mathrm{M}_{\mathrm{SR}}=3.38, \mathrm{SD}_{\mathrm{SR}}=0.67,(\mathrm{Min}=1.05$, $\mathrm{Max}=4.75)$, Life Disruption scores in the range of $\mathrm{M}_{\mathrm{LD}}=$ $2.34, \mathrm{SD}_{\mathrm{LD}}=0.68,(\mathrm{Min}=1.00, \mathrm{Max}=4.36)$ and Affective Reactions scores in the range of $\mathrm{M}_{\mathrm{AR}}=2.91, \mathrm{SD}_{\mathrm{AR}}=0.83$ $(\operatorname{Min}=1.00, \operatorname{Max}=4.71)$.

Test-retest reliability of the O-FAQ There was a strong, significant, correlation between Time 1 and Time 2 responses to the O-FAQ's Social Rumination $(r(311)=.86,95 \%$ CI [.83, $.89], p<.001)$, Life Disruption $(r(311)=.80,95 \%$ CI $[.76$, $.84], p<.001)$ and Affective Reactions $(r(311)=.72,95 \% \mathrm{CI}$ $[.66, .77], p<.001)$ scores, demonstrating the test-retest reliability of the factors.

O-FAQ and trait measures Table 3 reports the correlations between the Big Five traits and the O-FAQ domains. Social Rumination correlated positively to Agreeableness, Neuroticism, and Extraversion, supporting that this factor contains social activity and rumination traits. Similarly, Life Disruption is negatively correlated to Conscientiousness and positively related to Extraversion. Affective Reactions is validated by the positive correlation with Neuroticism and the negative correlation with the planful trait Conscientiousness.

Table 4 reports the planned two-stage regressions testing first the effect of age, gender, and time with friends and then in a further model with the Big Five traits included. In all models, younger age was associated with higher O-FAQ scores and, apart from Affective Reactions, more time with friends predicted higher scores on the O-FAQ. Gender did not predict domain scores. The inclusion of the Big Five traits improved all models (see Table 4), with the same pattern of significance as in the correlation analysis.

O-FAQ and problematic behavior Presented in Table 3 are the correlations between DOSPERT (risk-taking) behavior and the O-FAQ domains. Social Rumination was positively associated with Recreational, Health, Ethical, and Financial risktaking. Life Disruption was positively associated with Recreational, Health, Ethical, and Financial risk behaviors, and Affective Reactions was positively associated with Health and Ethical risks. In summary, there is evidence of the O-FAQ being positively related with risky behavior.

O-FAQ and reported time with friends At Time 1 the responses to the O-FAQ factors significantly positively correlated with the amount of time participants spent with friends in person over the last week; Social Rumination $(r(805)=.27$, $95 \%$ CI $[.21, .34], p<.001)$, Life Disruption $(r(805)=.39$, $95 \%$ CI $[.33, .44], p<.001)$, and Affective Reactions $(r(805)$ $=.14,95 \% \mathrm{CI}[.07, .21], p<.001)$. The correlation was similar in the Time 2 data; Social Rumination $(r(311)=.27,95 \%$ CI $[.17, .37], p<.001)$, Life Disruption $(r(311)=.42,95 \% \mathrm{CI}$ $[.33, .51], p<.001)$, and Affective Reactions $(r(311)=.27$, $95 \%$ CI $[.16, .37], p<.001)$.

Offline Friend Addiction prevalence The O-FAQ has 37 items. To be classified as an 'addict' using the conservative monothetic criteria, participants needed to provide 37 responses of Neither Agree nor Disagree (3) or higher. For the liberal polythetic criteria, participants would need to provide a response of 3 or higher on 19 items. On average, across the items, participants gave an answer that was coded as 3 or higher on $22 / 37$ items $\left(M_{>3}=21.81, \mathrm{SD}_{>3}=7.41\right.$, $\mathrm{Min}=$ $0, \operatorname{Max}=37$ ).

By the monothetic criteria, we conservatively estimate that, in our full Time 1 sample only five participants $(0.62 \%)$ were addicted to spending time with their friends. However, in line with similar studies, when using the suggested liberal polythetic classification to form our estimate of the prevalence of offline friend addiction, 558 participants $(69 \%)$ of the sample were addicts. This polythetic classification is predictable using the amount of time people spend with their friends, $(\beta=$ $.04, \mathrm{z}=6.32, p<.001)$. Further, the addiction classification can be predicted with low Openness $(\beta=-.43, \mathrm{z}=3.21, p=$ $.001)$, low Conscientiousness $(\beta=-.47, \mathrm{z}=3.62, p<.001)$, high Extraversion $(\beta=.62, \mathrm{z}=5.86, p<.001)$ and high Neuroticism $(\beta=.52, \mathrm{z}=4.88, p<.001)$.

\section{Discussion}

Social media addiction scales often classify people as 'addicted' if they engage in higher levels of social information seeking (e.g. Andreassen et al., 2012). As people might also seek social information in offline contexts, we reworded existing measures of social media 'addiction' to an offline friend addiction context. Using a precedent-defined classification of addiction, we found that $69 \%$ of our sample were addicted to their friends, even when offline. On the surface, the prevalence of addicts in this study would present a public health crisis for traditional classes of addiction. However, this is clearly not the case. The remarkably high classification number should make researchers reflect on the literature precedent for classifying 'pathological' social behavior.

One would hopefully recognize that conceptually (and indeed pragmatically) this measure is sardonic. 'Offline friend addiction' is not an issue of concern for public health, but rather it is capturing the psychology of relatedness seeking and experiences pertinent to social support, adaptation, and well-being across the lifespan (Gauze, Bukowski, AquanAssee, \& Sippola, 1996; Hartup \& Stevens, 1999). Being addicted to spending time with friends is not a recognized psychopathology within academic, clinical, or social domains, 
Table 2 The model fit criteria for the O-FAQ item reduction

\begin{tabular}{|c|c|c|c|c|c|}
\hline Factors & RMSEA & TLI & $\chi^{2}$ significance & $\chi^{2} /$ df ratio & Eigenvalues \\
\hline Target fit ${ }^{\mathrm{a}}$ & $<.08$ & $>.90$ & $p<.05$ & $<5.00$ & N/A \\
\hline One factor & $.097[.092, .098]$ & .61 & $p<.001$ & 7.16 & 10.57 \\
\hline Two factor & $.081[.075, .082]$ & .73 & $p<.001$ & 5.08 & 2.44 \\
\hline Three factor & $.070[.064, .072]$ & .80 & $p<.001$ & 3.91 & 1.37 \\
\hline Four factor & $.062[.056, .064]$ & .85 & $p<.001$ & 3.11 & 0.85 \\
\hline Five factor & $.054[.048, .056]$ & .88 & $p<.001$ & 2.50 & 0.53 \\
\hline Six factor & $.050[.043, .053]$ & .90 & $p<.001$ & 2.14 & 0.47 \\
\hline Seven factor & $.047[.040 . .050]$ & .91 & $p<.001$ & 1.89 & 0.30 \\
\hline
\end{tabular}

Notes. Target criteria presented in the top row. Bold indicates fit meets criteria.

Parallel analysis suggests six factors.

' Target fit as defined by Savci and Griffiths' (2019) table. These criteria are present in our preregistration

nor should it be. We do not advocate the creation of a friend addiction construct. However, it is worth considering how easy it was to classify individuals as pathologically seeking social information using minor adaptations of the instruments used in the context of social networking sites (e.g., Facebook). Interestingly, the original measures have been used as a basis for claims of public health concerns about social networking online (e.g., Andreassen et al., 2012). Our results confirm that researchers can quickly produce farcical results when conceptualizing social media as a distinctive entity to any other social context, akin to the risk of 'overpathologizing' everyday life (Billieux, Schimmenti, Khazaal, Maurage, \& Heeren, 2015). Seeking information from others about their lives or turning to friends when we feel lonely or bored is to be a social being. However, the wealth of current social media 'addiction' research is confounded by failing to demonstrate how these behaviors are unique or divergent from offline social behavior. This also speaks to how behavioral science often considers the impact of technology on everyday life. For example, related work demonstrate that scales that pertain to technology interactions capture sub-facets of mental health rather than actual technology-use behaviors (Davidson, Shaw, \& Ellis, 2020).

We are not the first to follow the behavioral addiction literature methodology closely and end with unusual conclusions. There have been concerns raised that existing conceptualizations of behavioral addiction rely on a framework that pathologizes activities that people engage with passionately, by medicalizing repetitive behavior as problematic (Starcevic, Billieux, \& Schimmenti, 2018). For example, a recent satirical study measured participants' 'addiction' to Star Wars universe (card) games, as an offline equivalent to Internet Gaming Disorder (Calvo, Carbonell, Oberst, \& Fuster, 2018). They observed that while stated motives to play, such as the desire to explore and socialise, mirrored constructs identified in IGD studies, regular users could not be classified as pathologically 'addicted' (Calvo et al., 2018). Calvo et al. called "for caution in diagnosing behavioral addictions; we should refer to other explanatory models such as the passion model or high involvement in an activity" (p. 734). Our findings are in line with these conclusions. We should be notably cautious in the development of novel behavioral addictions in the absence of clear psychiatric criteria or norms. This is particularly important when these behaviors may simply have high scores by their norms. This is the case with social-oriented behavior, where individuals have generally high levels of social interest. While social media addiction is readily pathologized by many researchers, the social processes behind scale questions are social-seeking behaviors, which are prima facie not pathological (and maybe even symptomatic of good well-being) when rephrased to focus on other forms of social behavior. The aim of this study was to sardonically highlight measurement and conceptual issues with developing of novel social media 'addiction' scales without due consideration for individuals' broader social information seeking behavior. We hope that future research in this area will think carefully about their use of scales to capture human behavior which takes place via digital means.

Another explanation for the apparent prevalence of offline friend addicts (as per the current study) and social media addicts (as per previous research) may be the use of polythetic scoring techniques. For example, behavioral addiction diagnoses are often categorically defined on the basis of individuals simply 'neither agreeing nor disagreeing' with an arbitrary number of symptoms. This is not a norm-based approach, which is standard in most attempts to identify atypical or pathological behavior. These techniques may present a threshold that is too low to identify 'unusual' behavior. Others have noted similar issues with the polytheticcategorical approach (see Cooper, Balsis, \& Zimmerman, 2010). Without a norm-based approach to creating cut-off scores, we are diagnosing an addiction based on researchers' heuristics of how their questionnaires should be responded to. 
Table 3 Correlations between the Big Five personality traits, DOSPERT domains and full-time 1 O-FAQ factor scores

\begin{tabular}{|c|c|c|c|}
\hline \multirow[t]{2}{*}{ Validation measure } & \multicolumn{3}{|c|}{$\begin{array}{l}\text { Offline-Friend Addiction Questionnaire domain } \\
\underline{r} \underline{[95 \% \mathrm{CI}](\mathrm{p})}\end{array}$} \\
\hline & Social rumination & Life disruption & Affective reactions \\
\hline \multicolumn{4}{|l|}{ Big Five traits } \\
\hline Conscientiousness & $-.08[-.15,-.01](.022)$ & $-.27[-.33,-.20](<.001)^{*}$ & $-.21[-.28,-.15](<.001)^{*}$ \\
\hline Agreeableness & $.12[.05, .19](<.001)^{*}$ & $-.11[-.17,-.04](.003)$ & $-.04[-.11, .03](.236)$ \\
\hline Neuroticism & $.16[.09, .22](<.001)^{*}$ & $.04[-.03, .10](.319)$ & $.34[.28, .40](<.001)^{*}$ \\
\hline Openness & $-.05[-.12, .02](.138)$ & $-.06[-.12, .01](.111)$ & $-.05[-.12, .02](.160)$ \\
\hline Extraversion & $.21[.14, .28](<.001)^{*}$ & $.12[.05, .19](<.001)^{*}$ & $.09[.02, .15](.015)$ \\
\hline \multicolumn{4}{|l|}{ DOSPERT domains } \\
\hline Social risk & $-.02[-.09, .05](.555)$ & $-.04[-.11, .03](.306)$ & $-.08[-.15,-.01](.029)$ \\
\hline Recreational risk & $.19[.12, .25](<.001)^{*}$ & $.20[.13, .27](<.001)^{*}$ & $.06[-.00, .13](.067)$ \\
\hline Health risk & $.15[.09, .22](<.001)^{*}$ & $.28[.21, .35](<.001)^{*}$ & $.13[.06, .20](<.001)^{*}$ \\
\hline Ethical risk & $.13[.06, .19](<.001)^{*}$ & $.27[.21, .34](<.001)^{*}$ & $.19[.12, .25](<.001)^{*}$ \\
\hline Financial risk & $.12[.05, .18](<.001)^{*}$ & $.21[.15, .28](<.001)^{*}$ & $.09[.02, .16](.009)$ \\
\hline
\end{tabular}

Notes. $d f=805, * p<.001$

For example, relying on a component model of behavioral addiction (e.g., Griffiths, 2005; Kuss \& Griffiths, 2017) to develop scales allows researchers to generate a limitless number of pathologies (including friendship addiction) with almost no theoretical foundation.

Currently, the discourse on issues around measurement and validity in psychology is still growing. Much needed attention has been drawn to 'questionable measurement practices' and risks to the internal, external, statistical, and construct validity of new scales (Flake \& Fried, 2019). In general, amidst discussions of replication, theory, and confidence crises in psychology (see Oberauer \& Lewandowsky, 2019; Pashler \& Wagenmakers, 2012), conversations about validity have been under-represented. This is, in part, due to validity being hard to define as a concept (Borsboom, Mellenbergh, \& Van Heerden, 2004), but also due to challenges with statistically demonstrating validity. As with the current study (and those it imitates) 'validation' is a process of associating novel measures, with their measurement and construct assumptions, with similar extant measures in a problematic tautological 'jingle-jangle' fallacy. These attempts at validation in the social media addiction literature could simply be converging on participant response patterns or latent factors that are mis-

Table 4 Regression models testing age, gender, and time with friends as predictors of the O-FAQ domains (model 1) with a comparison model including the Big Five (model 2) as estimates (with $p$ values in brackets)

\begin{tabular}{llll}
\hline & Social rumination & Life disruption & Affective reactions \\
\hline Model 1 & $R_{\text {Adj }}^{2}=.17(<.001)^{*}$ & $R_{\text {Adj }}^{2} .21(<.001)^{*}$ & $R_{\text {Adj }}^{2}=.08(<.001)^{*}$ \\
Age & $-0.02(<.001)^{*}$ & $-0.02(<.001)^{*}$ & $-0.02(<.001)^{*}$ \\
Gender & $-0.06(.213)$ & $0.13(.011)$ & $-0.04(.521)$ \\
Time with friends & $0.01(<.001)^{*}$ & $0.01(<.001)^{*}$ & $0.00(.063)$ \\
Model 2 & $R_{\text {Adj }}^{2}=.25(<.001)^{*}$ & $R_{\text {Adj }=.27(<.001)^{*}}^{2}$ & $R_{\text {Adj }}^{2}=.21(<.001)^{*}$ \\
& $\Delta R^{2}=.08(<.001)^{*}$ & $\Delta R^{2}=.06(<.001)^{*}$ & $\Delta R^{2}=.13(<.001)^{*}$ \\
Age & $-0.02(<.001)^{*}$ & $-0.02(<.001)^{*}$ & $-0.01(<.001)^{*}$ \\
Gender & $0.04(.495)$ & $0.06(.226)$ & $0.09(.188)$ \\
Time with friends & $0.01(<.001)^{*}$ & $0.01(<.001)^{*}$ & $0.00(.078)$ \\
Conscientiousness & $-0.01(.811)$ & $-0.17(<.001)^{*}$ & $-0.15(<.001)^{*}$ \\
Agreeableness & $0.13(<.001)^{*}$ & $-0.11(<.001)^{*}$ & $0.03(.517)$ \\
Neuroticism & $0.14(<.001)^{*}$ & $-0.03(.351)^{*}$ & $0.34(<.001)^{*}$ \\
Openness & $0.03(.380)$ & $0.06(.079)$ & $0.03(.554)$ \\
Extraversion & $0.18(<.001)^{*}$ & $0.11(<.001)^{*}$ & $0.20(<.001)^{*}$ \\
\hline
\end{tabular}

$* p<.001$ 
labeled by different researchers (Davidson et al., 2020). Operationalization of novel psychological constructs remains a challenge for the whole of psychology, but there should be particular caution when developing novel psychopathology measures. We urge caution, patience, and collaboration with informed psychiatric practice before developing novel psychopathologies.

\section{Conclusions}

We translated social media addiction measures into an offline friend addiction questionnaire and discovered $69 \%$ of our large sample would be classified as addicts. This demonstrates the risks of following common procedures in the social media addiction sub-field when developing new 'addiction' scales. To be clear, we do not advocate creating a diagnosis of offline friend addiction. The O-FAQ was created to highlight risks with psychopathologically themed research which lacks meaningful psychiatric validation criteria and uses liberal scoring for classification. Future social media research should focus on testing what components of social media use are distinct to offline social information seeking, especially if attempting to pathologize everyday behavior.

Open practices statement This study was preregistered and all materials we hold the copyright for, data and code are available on the OSF here: https://osf.io/9y2rh/

Author contributions We note that LS is the lead author, with equal second authors of DF, CAH, and HS. All other authors are listed alphabetically. Contributions are as follows; LS conceived the project and was principal lead. LS, DF, and CAH contributed to early project development. Project was reviewed and improved by BD, HS, DAE, CMH, LK, GL, and AJ. Ethical approval was sought by DF and LS. Material set up and study administration was led by HS and LS. All authors contributed to data collection. Manuscript writing was led by LS with input from LK. Significant revisions to the first draft of the manuscript were provided by $\mathrm{DF}, \mathrm{CAH}, \mathrm{DAE}, \mathrm{CMH}$, and LK. Further ocmments following peer review were provided by BD. DAE and HS. All others provided approval for the final paper submission. This is the first project under the Researching Engagement in Digital and Technological Environments for Advancing Measurement (REDTEAM) collaboration network.

Funding This project received no specific funding from internal or external bodies.

\section{Compliance with ethical standards}

Conflict of interest The author(s) declare that there are no conflicts of interest with respect to the authorship or the publication of this article.

Supplemental Material All data and scripts are available on the OSF: https://osf.io/9y2rh/

Prior versions A preprint of this work can be found on the psyarxiv at https://psyarxiv.com/7x $85 \mathrm{~m}$

\section{References}

Andreassen, C. S. (2015). Online social network site addiction: A comprehensive review. Current Addiction Reports, 2(2), 175-184. https://doi.org/10.1007/s40429-015-0056-9

Andreassen, C. S., Pallesen, S., \& Griffiths, M. D. (2017). The relationship between addictive use of social media, narcissism, and selfesteem: Findings from a large national survey. Addictive Behaviors, 64, 287-293. https://doi.org/10.1016/j.addbeh.2016.03. 006

Andreassen, C. S., Torsheim, T., Brunborg, G. S., \& Pallesen, S. (2012). Development of a Facebook Addiction Scale. Psychological Reports, 110(2), 501-517. https://doi.org/10.2466/02.09.18.pr0. 110.2.501-517

Billieux, J., Schimmenti, A., Khazaal, Y., Maurage, P., \& Heeren, A. (2015). Are we overpathologizing everyday life? A tenable blueprint for behavioral addiction research. Journal of behavioral addictions, 4(3), 119-123. https://doi.org/10.1556/2006.4.2015.009

Błachnio, A., \& Przepiorka, A. (2019). Be Aware! If you start using Facebook problematically you will feel lonely: Phubbing, loneliness, self-esteem and Facebook intrusion. A cross-sectional study. Social Science Computer Review, 37(2), 270-278. https://doi.org/ 10.1177/0894439318754490

Błachnio, A., Przepiorka, A., \& Pantic, I. (2016). Association between Facebook addiction, self-esteem and life satisfaction: A cross-sectional study. Computers in Human Behavior, 55, 701-705. https:// doi.org/10.1016/j.chb.2015.10.026

Blais, A. R., \& Weber, E. U. (2006). A domain-specific risk-taking (DOSPERT) scale for adult populations. Judgment and Decision Making, 1(1).

Borsboom, D., Mellenbergh, G. J., \& Van Heerden, J. (2004). The concept of validity. Psychological review, 111(4), 1061.

Brailovskaia, J., Margraf, J., \& Köllner, V. (2019). Addicted to Facebook? Relationship between Facebook Addiction Disorder, duration of Facebook use and narcissism in an inpatient sample. Psychiatry research, 273, 52-57. https://doi.org/10.1016/j. psychres.2019.01.016

Brailovskaia, J., Schillack, H., \& Margraf, J. (2018). Facebook addiction disorder in Germany. Cyberpsychology, Behavior, and Social Networking, 21(7), 450-456. https://doi.org/10.1089/cyber.2018. 0140

Calvo, F., Carbonell, X., Oberst, U., \& Fuster, H. (2018). May the passion be with you: The addictive potential of collectible card games, miniatures, and dice of the Star Wars universe. Journal of Behavioral Addictions, 7(3), 727-736. https://doi.org/10.1556/2006.7.2018.73

Chan, M. (2018b). Digital communication and psychological well-being across the life span: Examining the intervening roles of social capital and civic engagement. Telematics and Informatics, 35(6), 17441754. https://doi.org/10.1016/j.tele.2018.05.003

Chan, M. (2018a). Mobile-mediated multimodal communications, relationship quality and subjective well-being: An analysis of smartphone use from a life course perspective. Computers in Human Behavior, 87, 254-262. https://doi.org/10.1016/j.chb.2018. 05.027

Cooper, L. D., Balsis, S., \& Zimmerman, M. (2010). Challenges associated with a polythetic diagnostic system: Criteria combinations in the personality disorders. Journal of Abnormal Psychology, 119(4), 886-895. https://doi.org/10.1037/a0021078.

Davidson, B.I., Shaw, H., \& Ellis, D.A. (2020). Fuzzy Constructs in Assessment: The Overlap between Mental Health and Technology 'Use'. PsyArXiv. https://doi.org/10.31234/osf.io/6durk

Day, F. R., Ong, K. K., \& Perry, J. R. B. (2018). Elucidating the genetic basis of social interaction and isolation. Nature Communications, 9(1), 1-6. https://doi.org/10.1038/s41467-018-04930-1 
Deci, E. L., \& Ryan, R. M. (1985). Intrinsic motivation and selfdetermination in human behavior. New York, NY: Plenum

Deters, F. G., \& Mehl, M. R. (2013). Does posting Facebook status updates increase or decrease loneliness? An online social networking experiment. Social Psychological and Personality Science, 4(5), 579-586 https://doi.org/10.1177/1948550612469233

Ellison, N. B., Steinfield, C., \& Lampe, C. (2007). The benefits of Facebook "friends": Social capital and college students' use of online social network sites. Journal of Computer-Mediated Communication, 12(4), 1143-1168. https://doi.org/10.1111/j.10836101.2007.00367.x

Elphinston, R. A., \& Noller, P. (2011). Time to face it! Facebook intrusion and the implications for romantic jealousy and relationship satisfaction. Cyberpsychology, Behavior, \& Social Networking, 14(11), 631-635. https://doi.org/10.1089/cyber.2010.0318

Flake, J. K., \& Fried, E. I. (2019). Measurement Schmeasurement: Questionable Measurement Practices and How to Avoid Them. https://doi.org/10.31234/osf.io/hs7wm

Gauze, C., Bukowski, W. M., Aquan-Assee, J., \& Sippola, L. K. (1996). Interactions between family environment and friendship and associations with self-perceived well-being during early adolescence. Child Development, 67(5), 2201-2216. https://doi.org/10.1111/j. 1467-8624.1996.tb01852.x

Gheorghiu, A., Delhomme, P., \& Felonneau, M. L. (2015). Peer pressure and risk taking in young drivers' speeding behavior. Transportation research part $F$ : traffic psychology and behavior, 35, 101-111.

Griffiths, M. (2005). A 'components' model of addiction within a biopsychosocial framework. Journal of Substance Use, 10(4), 191-197.

Gul, H., Yurumez Solmaz, E., Gul, A., \& Oner, O. (2018). Facebook overuse and addiction among Turkish adolescents: are ADHD and ADHD-related problems risk factors?. Psychiatry and Clinical Psychopharmacology, 28(1), 80-90. https://doi.org/10.1080/ 24750573.2017.1383706

Hartup, W. W., \& Stevens, N. (1999). Friendships and adaptation across the life span. Current Directions in Psychological Science, 8(3), 7679. https://doi.org/10.1111/1467-8721.00018

Hou, Y., Xiong, D., Jiang, T., Song, L., \& Wang, Q. (2019). Social media addiction: Its impact, mediation, and intervention. Cyberpsychology: Journal of Psychosocial Research on Cyberspace, 13(1), https://doi.org/10.5817/CP2019-1-4

Jafarkarimi, H., Sim, A. T. H., Saadatdoost, R., \& Hee, J. M. (2016). Facebook addiction among Malaysian students. International Journal of Information and Education Technology, 6(6), 465. https://doi.org/10.7763/IJIET.2016.V6.733

John, O. P., Naumann, L. P., \& Soto, C. J. (2008). Paradigm shift to the integrative Big Five trait taxonomy: History, measurement, and conceptual issues. In O. P. John, R. W. Robins, \& L. A. Pervin (Eds.), Handbook of personality: Theory and research (pp. 114-158). New York, NY: Guilford Press.

Kuss, D. J., \& Griffiths, M. D. (2017). Social networking sites and addiction: Ten lessons learned. International Journal of Environmental Research and Public Health, 14, 311. https://doi. org/10.3390/ijerph14030311.

Lewis, C. E., \& Lewis, M. A. (1984). Peer pressure and risk-taking behaviors in children. American Journal of Public Health, 74(6), $580-584$.

Lin, J.-H. (2016). Need for relatedness: a self-determination approach to examining attachment styles, Facebook use, and psychological wellbeing. Asian Journal of Communication, 26(2), 153-173. https:// doi.org/10.1080/01292986.2015.1126749
Martín-Albo, J., Lombas, A. S., Jiménez, T. I., Valdivia-Salas, S., Núñez, J., \& León, J. (2015). The mediating role of relatedness between repair and loneliness: A preliminary model in high school students. Journal of Happiness Studies, 16(5), 1131-1148. https://doi.org/10. 1007/s10902-014-9550-3

Oberauer, K., \& Lewandowsky, S. (2019). Addressing the theory crisis in psychology. Psychonomic bulletin \& review, 26(5), 1596-1618.

Obst, P., \& Stafurik, J. (2010). Online we are all able bodied: Online psychological sense of community and social support found through membership of disability-specific websites promotes well-being for people living with a physical disability. Journal of Community \& Applied Social Psychology, 20(6), 525-531. https://doi.org/10. 1002/casp.1067

Orosz, G., Tóth-Király, I., \& Bőthe, B. (2016). Four facets of Facebook intensity - The development of the Multidimensional Facebook Intensity Scale. Personality and Individual Differences, 100, 95104. https://doi.org/10.1016/j.paid.2015.11.038

Pashler, H., \& Wagenmakers, E. J. (2012). Editors' introduction to the special section on replicability in psychological science: A crisis of confidence?. Perspectives on Psychological Science, 7(6), 528-530.

Rajesh, T., \& Rangaiah, B. (2020). Facebook addiction and personality. Heliyon, 6(1), https://doi.org/10.1016/j.heliyon.2020.e03184

Reis, H. T., Sheldon, K. M., Gable, S. L., Roscoe, J., \& Ryan, R. M. (2000). Daily Well-Being: The Role of Autonomy, Competence, and Relatedness. Personality and Social Psychology Bulletin, 26(4), 419-435. https://doi.org/10.1177/0146167200266002

Sampath, H., Kalyani, S., Soohinda, G., \& Dutta, S. (2017). Patterns, attitudes, and dependence toward WhatsApp among college students. Journal of Mental Health and Human Behavior, 22(2), 110.

Savci, M., \& Griffiths, M. D. (2019). The Development of the Turkish Social Media Craving Scale (SMCS): a Validation Study. International Journal of Mental Health and Addiction https://doi. org/10.1007/s11469-019-00062-9

Sheldon, K. M., Abad, N., \& Hinsch, C. (2011). A two-process view of Facebook use and relatedness need-satisfaction: Disconnection drives use, and connection rewards it. Journal of Personality and Social Psychology, 100(4), 766-775. https://doi.org/10.1037/ a0022407

Starcevic, V., Billieux, J., \& Schimmenti, A. (2018). Selfitis and behavioral addiction: A plea for terminological and conceptual rigour. Australian and New Zealand Journal of Psychiatry, 52(10), 919920. https://doi.org/10.1177/0004867418797442

Stieger, S. \& Lewetz, D. (2018). A week without using social media: Results from an ecological momentary intervention study using smartphones. Cyberpsychology, Behavior and Social Networking, 21(10), 618-624. https://doi.org/10.1089/cyber.2018.0070

Subrahmanyam, K., Reich, S. M., Waechter, N., \& Espinoza, G. (2008). Online and offline social networks: Use of social networking sites by emerging adults. Journal of Applied Developmental Psychology, 29(6), 420-433. https://doi.org/10.1016/j.appdev.2008.07.003

Twenge, J. (2017). Have Smartphones Destroyed a Generation? Retrieved February 19, 2018 fromhttps://www.theatlantic.com/ magazine/archive/2017/09/has-the-smartphone-destroyed-ageneration/534198/ https://www.theatlantic.com/magazine/archive/ 2017/09/has-the-smartphone-destroyed-a-generation/534198/

Wang, T., Brede, M., Ianni, A., \& Mentzakis, E. (2018). Social interactions in online eating disorder communities: A network perspective. PloS one, 13(7). https://doi.org/10.1371/journal.pone.0200800

Publisher's note Springer Nature remains neutral with regard to jurisdictional claims in published maps and institutional affiliations. 